\title{
Socioeconomic Evaluation of Drought Effects. Main Principles and Application to Guadiana and Algarve Case Studies
}

\section{Rodrigo Maia, Eduardo Vivas, Ricardo Serralheiro \& Mário de Carvalho}

Water Resources Management

An International Journal - Published for the European Water Resources Association (EWRA)

ISSN 0920-4741

Water Resour Manage

DOI 10.1007/s11269-014-0883-9

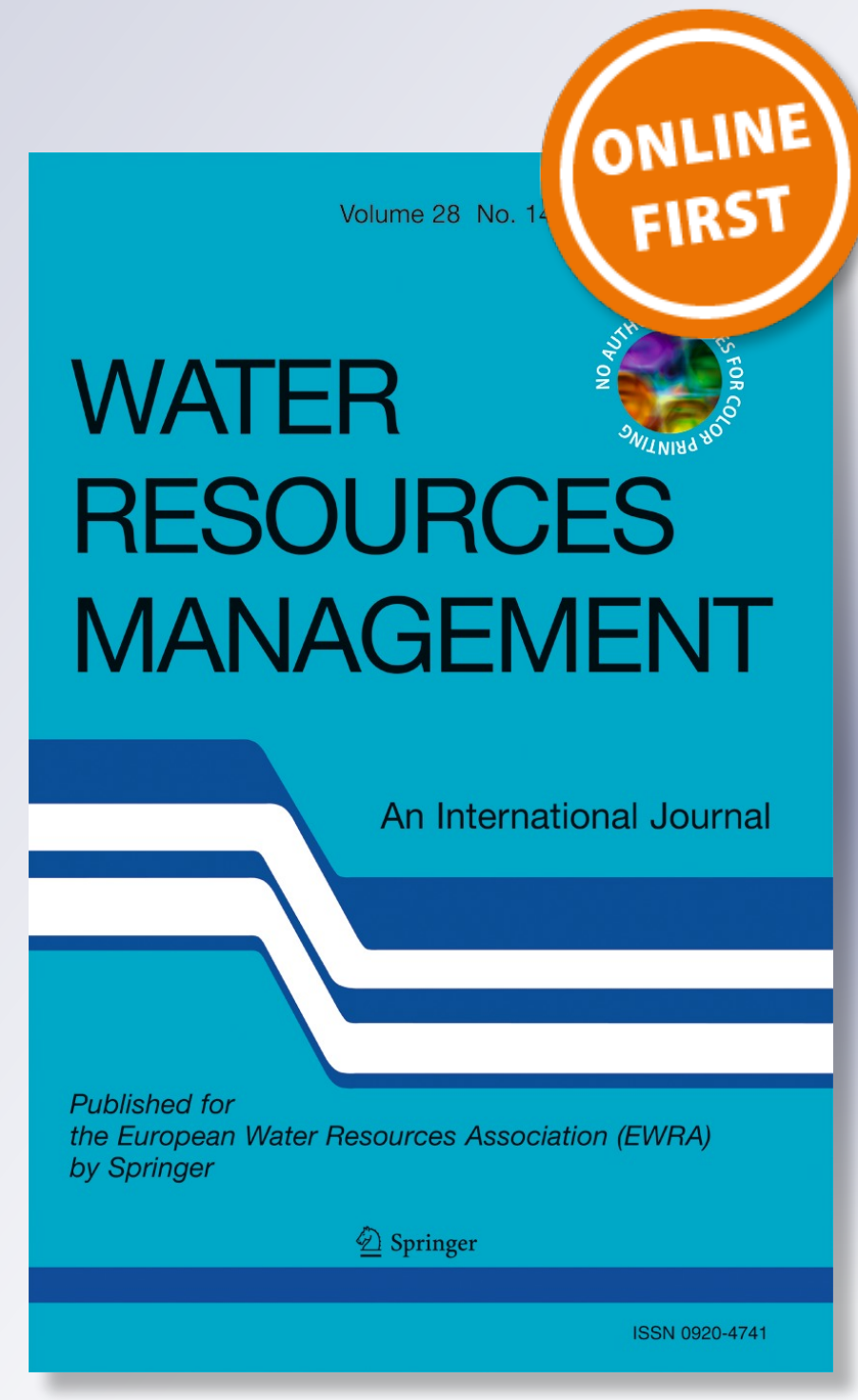

黛 Springer 
Your article is protected by copyright and all rights are held exclusively by Springer Science +Business Media Dordrecht. This e-offprint is for personal use only and shall not be selfarchived in electronic repositories. If you wish to self-archive your article, please use the accepted manuscript version for posting on your own website. You may further deposit the accepted manuscript version in any repository, provided it is only made publicly available 12 months after official publication or later and provided acknowledgement is given to the original source of publication and a link is inserted to the published article on Springer's website. The link must be accompanied by the following text: "The final publication is available at link.springer.com". 


\title{
Socioeconomic Evaluation of Drought Effects. Main Principles and Application to Guadiana and Algarve Case Studies
}

\author{
Rodrigo Maia • Eduardo Vivas • Ricardo Serralheiro • \\ Mário de Carvalho
}

Received: 3 January 2014 / Accepted: 11 November 2014

(C) Springer Science+Business Media Dordrecht 2014

\begin{abstract}
Drought situations can have significant impacts, affecting large areas and imposing relevant restrictions on multiple economic activities. The severity of those impacts is, normally, assessed through meteorological, agricultural and/or hydrological indices or even through estimation of water deficits or reduction of production yields (for agriculture). However, those assessments usually do not represent the socioeconomic importance of the impacts and the results are not comparable for different types of impacts or distinct regions. In this context, the present work enunciates the main principles to be considered and a methodological approach for socioeconomic evaluation of drought effects, regarding the main supply and demand characteristics of a region (water sources and associated uses), and the hydrological interlinked effects of drought situations. Moreover it describes the methodology process application to Portuguese reality and existing data as the basis of drought's severity assessment, focusing on two drought prone areas in Portugal: the Guadiana and the Ribeiras do Algarve river basin case studies. Regarding the main specificities of the referred case studies, the economic activities (and water dependent sectors) considered for this methodology were the agricultural and the urban water supply sectors. For each of those sectors, specific assessment procedures where developed in order to estimate the respective economic impacts caused by the drought situation in the area of analysis. A global assessment of the socioeconomic relevance of drought impacts in a region is ensured through comparison of the estimated total economic impacts to the region's annual average of the Gross Domestic Product (GDP), that enabling the comparison
\end{abstract}

\footnotetext{
R. Maia $(\bowtie) \cdot$ E. Vivas

Division of Hydraulics, Water Resources and Environment; Civil Engineering Department; Faculty of Engineering, University of Porto, Rua Dr. Roberto Frias, s/n, 4200-465 Porto, Portugal

e-mail: rmaia@fe.up.pt

E. Vivas

e-mail: evivas@fe.up.pt

R. Serralheiro $\cdot$ M. de Carvalho

ICAAM (Institute of Agricultural and Environmental Sciences), University of Évora, Évora, Portugal

R. Serralheiro

e-mail: ricardo@uevora.pt

M. de Carvalho

e-mail: mjc@uevora.pt
} 
of results for different regions of analysis. The methodology may be applicable to any region with common hydrological and water use data and was developed to be of support for drought management and application on a drought early warning system.

Keywords Drought impacts · Socioeconomic assessment · Agricultural losses · Urban water supply sector's increased costs $\cdot$ Regional economic impact

\section{Introduction}

Drought situations can have significant impacts, affecting large areas and imposing relevant restrictions on multiple economic activities, especially in regions with semiarid climatic characteristics and intensifying water uses, as is the case of Southern Europe (DG Env 2007a; Iglesias et al. 2009; Strosser et al. 2012). The water dependent activities suffering from more significant impacts during drought situations are, most frequently, agriculture, urban water supply, energy production, industry and tourism (DG Env 2007a; Kraemer 2007).

The severity of drought impacts is, normally, assessed through meteorological, agricultural and/or hydrological indices (Steinmann et al. 2005; DG Env 2007b; Wilhite 2009). The importance of those impacts can also be estimated through quantification of water deficits or reduction of production yields (for agriculture). However, the referred assessments do not usually represent the socioeconomic importance of the impacts and also the obtained results are not directly comparable for different types of impacts or distinct regions (Kraemer 2007; Markandya and Mysiak 2010; Ding et al. 2011).

In this context, the present work enunciates the main principles to be considered for socioeconomic evaluation of drought effects, regarding the main supply and demand characteristics of a region (water sources and associated uses), as well as region's hydrological features

The corresponding drought's severity assessment methodology herein also presented (applied to two case study regions) was developed following those main principles and as the envisaged frame of a real drought management and early warning system adapted to Portuguese reality and existing data (Serralheiro et al. 2010; Vivas and Maia 2013).

Thus, the present article will: review the possible propagation (on time and water use sectors) of effects during drought situations (Section 2); enunciate the main principles of droughts' assessment based on the socioeconomic importance of drought impacts on a certain region, as well as of the existing methods for estimation of the economic value of drought effects, interlinking those to the general description of a methodological approach for drought's severity assessment (Section 3); describe the methodology process application to the Guadiana and Algarve case studies and discuss the results obtained for a significant drought situation in both regions, the hydrological year of 2004/2005 (Section 4) and, finally; consider the methodology outputs for exploring the assessment and comparison of different regions and drought situations (Section 5).

\section{Impacts of Drought Situations}

Droughts are a natural phenomenon, being part of climate variability in every region. Drought impacts result from the interaction between the corresponding natural anomaly in rainfall conditions, for the region and period under analysis, and the existing dependence of human 
activities on water and other natural resources, in that same region (Wilhite et al. 2007). Thus, during a drought situation (Kraemer 2007), and in terms of impacts, one may observe that:

- At the very beginning, there is a reduction of rainfall conditions that leads to a reduction on soil moisture.

- Thereafter, the first impacts appear on the agricultural sector due to soil moisture deficits, due to which a generalized reduction of crops production and productivity can occur. In fact, the severity of those impacts depends on: (i) the crop pattern of the area, (ii) crops' development phase, in which the water shortage occurs, (iii) the existence, or not, of water availability to compensate moisture deficits, in irrigated agriculture. On the other hand, a need to cover additional costs in order to compensate, for example, reduction of pastures for livestock husbandry (as enhanced by Pereira 2007) can, also, represent significant impacts.

- In urban water supply, even though to it legal priority does normally apply, important problems do still often occur, such as: (i) constrained supply periods, due to limited water availability, (ii) water use restrictions (for irrigation of gardens, street cleaning, car washing, etc.), or even (iii) competition for water rights with other sectors. On the other hand, additional costs may also be necessary to guarantee supply from alternative sources or improvement of water treatment levels.

- For energy production, the main impacts correspond to the reduction of water availability for hydropower or for thermal or nuclear power plants equipment's refrigeration.

- In the industry sector, the agro-food as well as the pulp and paper industries are the main subsectors affected, respectively due to the reduction and/or higher cost of the available raw agro materials and due to the slower development of forests vegetation or the increase of fires' risk.

- In the tourism and recreation sector, the impacts of a drought situation depend on the season and area affected, e.g., limitations on pool filling or golf courses irrigation on summer tourism.

Moreover, although more difficult to identify and assess, the social impacts of drought can also be very significant, corresponding to: (i) rural population decline, (ii) increase of unemployment, (iii) reduction of social cohesion, due to increase of conflicts, or even (iv) effects on individual physical and mental health, usually associated to depression and anxiety (Alston and Kent 2004; Wilhite and Buchanan-Smith 2005; Sartore et al. 2007).

\section{Socioeconomic Assessment of Droughts}

\subsection{Main Principles}

Although there is a wide experience on the assessment of drought situations using common drought indices, such as the Standardized Precipitation Index (McKee et al. 1993), or the PDSI (Palmer 1965), existing limitations are recognized on the interpretation of those indices' results, especially regarding the application of the respective severity classifications (Alley 1984; Agnew 2000). As referred by these authors, the problems arise from the difficulties on the adaptation of those indices to regional specificities (types of water uses, water sources, storage capacities, etc.), in order to accurately reflect the occurrence of drought impacts on different regions. 
As referred in Section 2, not only the level of moisture deficit resulting from a certain drought situation but also the characteristics of the existing water uses in the region at stake define the type and severity of the resulting drought impacts. Moreover, those effects are also dependent on the resilience and storage capacity of regional water sources, as well as on the characteristics of the main infrastructures and on the ability of the responsible institutions to cope with the drought situation.

Moreover, since drought can impact different types of water uses, and normally does affect several regions simultaneously, there is a need to make a comprehensive comparison of drought impacts' severity on different users, regions, and/or situations, in order to better support drought management. Therefore, a radically different approach shall be considered, ideally using a common frame that, simultaneously, allows a distinction of the relative importance of drought effects and also helps the selection of appropriate mitigation measures.

In order of that, economic valuation methods may play a key role, in accordance with those methods main goals, stressed by Colby (1989) and Green (2003) as: (i) to facilitate decision making, using a perceptible type of information; (ii) to clarify the relative importance of the components in stake, and; (iii) to set a common language for assessment and discussion among stakeholders. In that line, Markandya and Mysiak (2010) and Ding et al. (2011), for example, pointed out that the economic valuation techniques can be very important tools for drought impacts' evaluation, namely to assess the importance of drought impacts on different users, regions, and/ or drought situations and also to understand the monetary benefits of potential drought mitigation programs. In fact, the economic valuation methods have been and can be used for drought assessment, at least for estimation of an order of magnitude of drought impacts for a water sector and/or for a region. Several studies involving the valuation of economic losses of drought situations, on different water use sectors, may be referred: Dixon et al. (1996), Jenkins et al. (2003), Ward et al. (2001, 2006) and Valiñas (2006). On these studies, the economic valuation methods were used also for planning and management of possible future drought situations.

According to several studies related to water and natural resources economy (Gibbons 1986; Green 2003; Raucher et al. 2005; Birol et al. 2006), the main valuation methods applicable to water uses can be divided into two distinct categories, according to the base method for estimation of the economic value: (i) direct and (ii) indirect valuation methods.

The direct valuation methods include the use of market prices (determined through definition of demand functions) and stated preference methods (based on realization of surveys); the indirect valuation methods - such as the use of production functions, replacement cost or hedonic price methods -, are to be used when the good is not directly traded (as, for example, the use of water from own sources) or there is insufficient data to define the respective demand functions.

According to the main water uses at stake, and also to the usual available existing data, different valuation methods could be considered. In any case, the main purpose and advantage of the use of valuation methods for drought assessment is to transform water deficits estimations into relevant and useful information for water managers.

The economic value of overall drought impacts can be compared to regional Gross Domestic Product (GDP), as indicative of regional socioeconomic resilience and capacity to cope and adapt to drought situations (Iglesias et al. 2009). By means of this ratio, it is possible to compare different regions and identify those were interventions are more needed and urgent. 


\subsection{General Methodology}

The methodology developed takes, as a basis, the principles of drought's management risk. That risk over a certain region corresponds to the result of the combination of a possible meteorological hazard (anomaly of the precipitation conditions on the period considered) with the regional water vulnerabilities (due to water uses and water sources' storage).

The occurrence of a possible regional meteorological hazard is assessed by means of the variation of adequate hydrologic indicators, namely river flows, surface reservoirs storage and piezometric levels on aquifers. That aims at characterizing the main drought situations, based on historical records, through the anomalies on precipitation and the corresponding effects on the different monitored variables involved in the hydrologic cycle phases, and that enable also the assessment of water availabilities in the main regional water sources.

Based on that, the socio-economic assessment of drought impacts is made for all the main water use sectors (urban supply and agriculture), taking into account the specific regional sectorial water vulnerabilities, and namely the corresponding water abstractions and uses. The socio-economic valuation and assessment is done on a monthly basis at the global scale of the river basin, sub-divided on predefined operative unit of analysis, on a hydrological year time frame. The water sector's socio-economic specific evaluation process is following described and exemplified by the application to two case studies.

\section{Application to Guadiana and Algarve Case Studies}

In order to facilitate the evaluation of drought impacts' occurrence in a certain region, the socioeconomic assessment of droughts requires a continuous monitoring of the area, not only in what concerns rainfall anomalies and the consequent hydrological impacts (e.g. river discharge levels, volumes stored in reservoirs and aquifer systems, etc.), but also in what concerns supply of the existing water uses and identification of possible shortages. Therefore, this assessment shall regard the identification of particular problems within a region and foster the implementation of potential prevention and mitigation measures adequate to the existing problems, depending on a previous evaluation of water management characteristics. The case studies selected were the (Portuguese) Guadiana and the Ribeiras do Algarve river basins, representing the main diversity of water resource management realities' existing in Portugal. Being both considerable drought prone areas, the first corresponds to a transboundary river (shared with Spain, being Portugal downstream and under a common agreement on shared water resources management - the Albufeira Convention) and the second one located in Algarve administrative region, i.e. totally within Portuguese area.

Taking into account the above referred valuation methods necessary inputs (Section 3.), the production function and the replacements cost methods were considered the more appropriate economic valuation techniques to be the basis for a general socioeconomic evaluation of drought effects and comparison of the different regions and drought situations (Vivas 2011; Vivas and Maia 2013).

The main steps for application of the socioeconomic evaluation of drought effects for these two case studies are described below.

\subsection{Main Water Uses Considered}

Regarding the characteristics of both case studies, the most important water uses identified are the urban water supply and the agricultural sector (including livestock husbandry). It shall be 
referred that: (i) industry has a reduced importance in Guadiana (ARH-Alentejo 2012) and, therefore, was not considered and (ii) the tourism sector in Algarve - except golf courses, included in agricultural water use - was considered represented through urban water use sector.

\subsection{Assessment of Agricultural Losses}

Drought impacts on agriculture are assumed to be well represented by the values calculated for the losses in the agricultural sector caused by the limitations in crop water availability due to drought situation. The referred values should be calculated with current prices of agricultural production in the international market. In order of that, agricultural losses were calculated as the difference in production between the actual (drought influenced) situation and a normal (or potential) situation, evaluated by means of statistical data or estimated with convenient production functions. The calculations were carried out for every subsector in the agricultural sector and the results summed as to obtain the gross value of the agricultural losses. In the study, two agricultural subsectors were considered: 1) rainfed agriculture and 2) irrigated agriculture, this last differentiated into three systems in accordance to the irrigation water sources: public owned (large) reservoirs, private owned (small) reservoirs, private systems using groundwater. Each of these systems shows a particular behavior when adapting to drought conditions, defining specific relationships between meteorological and agricultural and hydrological drought.

The agricultural economic losses were estimated through quantification of water shortages and specific production functions, adapted to regional characteristics and to the main limitations of available data. Some important distinctions were also made, regarding the definition of appropriate procedures for the main types of agricultural practices in the regions, namely: rainfed agriculture, irrigated agriculture and, for the latter, according the type of water source used.

The general procedure in each spatial unit of analysis for most herbaceous rainfed and irrigated crops starts by calculating crop water requirements, or crop evapotranspiration ETc., according to the so called FAO crop coefficients methodology (Doorenbos and Kassam 1979; Allen et al. 1998). It is generally assumed that the availability of soil water enough for the crop consumption ETc. corresponds to the maximum or potential crop yield, which can be assumed statistically, or modelled, or estimated for each crop and each region.

The second step in this general procedure consists in carrying out a soil (with crop) water balance, which allows for the identification of normal rainfed situations or, otherwise, the water shortage situations and the irrigation requirements. The water balance and subsequent calculation of irrigation requirements was done with the ISAREG model (Teixeira and Pereira 1992), applying the FAO proposed methodology and crop coefficients. It is also generally assumed that, if a soil water shortage occurs, as due to a drought occurrence, crop yield will reduce accordingly. In order to account for such a reduction, the Stewart function, described as:

$$
(1-\mathrm{Ya} / \mathrm{Yc})=\mathrm{ky}(1-\mathrm{ETa} / \mathrm{ETc})
$$

was adopted in the ISAREG model, where ky is a crop sensitivity (to water shortage) coefficient ("yield coefficient"), Ya is crop yield corresponding to the water restricted consumption ETa, Yc is crop maximum or potential yield, corresponding to the maximum water consumption ETc.

For some rainfed herbaceous crops in the present work, as described in the next section, this general procedure was not applied, because crop specific production functions which are regionally known are assumed to account for more accurate relationships between rainfall and 
crop yield. Also for woody permanent crops, whether rainfed or irrigated, the ISAREG model was not applied, because the FAO recommended crop coefficients were not considered satisfactory for these crops. The procedure was then to use a spreadsheet based water balance calculation, experimenting crop coefficients and corresponding yields according to regional experience.

\subsubsection{Rainfed Agriculture}

Considering the analysis framed on the hydrological year time scale (from October to September), approximately correspondent to the agricultural year time scale, agricultural economic losses can be estimated through the reduction of annual production due to water availability limitation, compared to the average production levels in normal years. Gross production estimations are based on the agricultural areas identified in the nation-wide official agricultural inquiries carried out by the National Institute of Statistics each 10 years, the last one reporting to 2009 (INE 2011). In rainfed agriculture the reduction of production is directly related with the reduction of precipitation in the region, especially during the critical periods for each crops' development.

In fact, it was concluded that some rainfed crops (mainly cereals and pastures), in both case study regions, have two main critical periods that must be assessed in order to estimate possible losses of productivity due to drought: (i) November to February and (ii) March to April. The assessment of corresponding impacts is based on the evaluation of representative crops of different crop groups (cereals for grain, pulses, fodder and temporary pastures, etc.). For each individual crop, a water productivity function was defined, on the basis of the total precipitation occurring in the critical periods of analysis, to obtain the corresponding annual yield levels. The agricultural losses due to drought are, then, generally quantified by means of the reduction in productivity (considered a function of rainfall reduction on critical periods), and depending on the areas allocated to each representative crop. For pastures, however, the agricultural losses are quantified differently, since these do not correspond to a commercial product in the international market, namely due to the additional costs resulting from the need to acquire, in the regional market, hay and concentrate feed for livestock production, corresponding to the reduction of produced pastures.

\subsubsection{Irrigated Agriculture}

In what regards irrigated crops, the socioeconomic assessment of impacts due to droughts is also based on the reduction of annual production. In this case, the assessment requires the comparison of the available water (attending to possible use of water to complement rainfall shortages) in the hydrological year timescale, with crop demand needs (irrigation requirement) estimated for each representative crop group considered (maize/spring cereals, sunflower/oilseeds, wheat/winter cereals, tomato/industrial vegetables, rice, permanent pasture, olive groves, orchards, vineyards). These total needs, corresponding to the average needs for crops production in normal years, are estimated based on the areas allocated to each crop group, on average water irrigation requirement quantified for each crop group and on the efficiency of the irrigation methods used.

When a hydrological drought is identified (as a water for irrigation shortage in the source: public reservoir, private reservoir, aquifer), two options can be considered: whether to irrigate 
the normal area, reducing the water allocation to the fields (deficit irrigation), or to irrigate a reduced area with a normal volume allocation. Usually for annual crops the second option should be preferred by the farmer, because the production factors (and costs) will be reduced with the irrigated area. This option is not possible for permanent crops, on which deficit irrigation should be practiced, with the Stewart function (Eq. 1) being applied for the calculation of yield losses, as described before. For annual crops, the production losses due to the drought could be assumed as crop normal yield corresponding to the uncultivated area. It should be noted that, for a farmer decision on the referred reduction options, the drought situation and the corresponding water availability in water sources must be defined in time for the preparation of the agricultural and irrigation activities.

The water available for irrigation is defined according to the type of water source in use for the irrigated area. According to the case characteristics, three main types of water sources can be identified: (i) public water reservoirs, (ii) private small water reservoirs, (iii) groundwater (private abstractions).

In the case of public water reservoirs, the estimation of water availability is achieved through hydrological model balance developed specifically for each of the main public water reservoirs, attending to monthly real water storage volumes data, provided by a national information system on water resources (INAG 2011), and to inflows and outflows of those same reservoirs. The inflows are estimated in order to approximate the existing water volumes stored in each reservoir, according to the precipitation occurred up to the month of analysis, the discharges rules identified for each reservoir, the evaporation losses and the water consumptions dependent on the referred reservoir.

In what regards small private reservoirs, the main difference to public reservoirs is that the stored volumes are not monitored. Therefore availabilities have to be estimated based on the known reservoir's capacities, and assuming that, in a regular year, full capacity is always reached. In dry years, the available volume is a function of the regular runoff reduction given by hydrological models calibrated to simulate natural runoff generation in the area.

For irrigated areas relying on groundwater abstractions, the procedure for estimation of water availabilities differs with the type of bedrock formation supporting the underground water storage from which water is extracted:

- In the so called geologically non-differentiated area (NDA) that corresponds to a major part of the study regions, small storage capacity does exist due to the fractured nature of the ground systems, and also there is no groundwater monitoring. Therefore, a balance was assumed to exist between the water demand needs quantified as associated to these areas and the natural recharge in normal years. In drought years, the reduction in the available water is defined based on the reduction in precipitation when compared to the median for the region.

- For water abstractions located in differentiated aquifer systems, a hydrologic balance model is used to simulate the evolution of groundwater table records on the referred aquifer. The model takes into account existing water uses, losses due to evaporation, water springs and flow discharges to rivers and to other aquifer systems and estimates the necessary aquifer recharge as the one that, according to the precipitation levels and aquifer porosity, approximates the spatial average of groundwater table levels. Water availability in each aquifer system is, then, quantified according to the saturated height correspondent to the difference between groundwater table levels and the average abstraction depths, taking into account the average ground porosity in the area. 


\subsection{Assessment of Urban Water Supply Sector's Increased Costs}

Important limitations can occur in the region for urban water supply, during a drought situation, especially because in the case study areas there are water sources of limited capacity and water systems with low or no flexibility for management of different water sources' availabilities. In accordance, the socioeconomic effects of drought in this sector were estimated through quantification of the additional costs necessary to offset water shortages with alternative sources. The corresponding economic conceptual basis, described in detail in Vivas (2011) and Vivas and Maia (2013), was adapted to regional specificities, namely in what regards quantification of water shortages for urban sector, as presented below.

Assuming that a water supply system is composed by a water abstraction, water transport pipes, and the final distribution network, it was possible to identify two main types of water systems in both case study regions: (i) the, so-called, autonomous systems (AS), dependent only on one type of water source (storage reservoir, aquifer system or non-differentiated area, NDA), as well as (ii) the, so-called, integrated systems (IS) served by more than one type of water sources, by that enabling generally management flexibility. The calculation of water demand, allocated to each water supply system, makes use of a Portuguese national inventory of water supply and wastewater drainage systems (INSAAR) database (INAG 2009) for determining the volumes of water abstracted from each source. It shall be referred that, taking into account the emergency nature of a drought situation, a reduction of $5 \%$ on urban water consumptions was assumed during that period, by means of water savings, as response due to public awareness.

The available water in each of the water supply systems, on a hydrological time scale (compatible with the assessment of agricultural losses), is estimated in accordance with the type of water source(s) on which they depend, the corresponding water availabilities defined similarly to the procedure described before (in 4.2.2).

In what concerns the integrated systems, the referred assessment shall take into consideration the global water needs of each of the systems and the total water availabilities of the corresponding sources, thereby simulating the possibility of using water from all the available sources within those systems. On the other hand, in what concerns the autonomous systems, it was assumed that a supply margin up from the water volume supplied in a normal situation does exist, (i) either given by availabilities from extra boreholes, dedicated to emergency situations, when existent, or (ii) correspondent to $20 \%$ of estimated water demand needs on a regular year, for the remaining situations.

Both in the autonomous and in the integrated systems, the water shortage volumes, considered as the difference between the (reduced in $5 \%$ ) water demand needs and the total availabilities of water sources, are used for estimation of the socioeconomic effects on this sector. The calculation is done by estimating the additional costs derived from the compensation of the water volumes in deficit, considering, as a reference for emergency situations, the use of water tanks, for smaller water supply volumes, and, for larger volumes, the execution of new, complementing, boreholes. For both cases, regional characteristic average costs $\left(\mathrm{m}^{3}\right.$ of water, for supplies by water tank, and meter of borehole execution, for new boreholes, the number of those determined by assuming the current boreholes productivity in the region) were considered. In order to ensure proximity to regional reality, a limit to the volume supplied through water tanks was considered. 


\subsection{Drought Severity Across Regions and Drought Situations}

The annual economic impacts of drought, estimated according to the previously described methodologies, for a particular hydrological year, can be aggregated: (i) by user sector, for a certain region, and (ii) by region, as a sum of the impacts for all sectors.

In the aggregation by user sector, the economic impacts obtained for each agricultural subsector shall be summed and compared with the total income for the agricultural sector in the same region, for a normal year (obtained through the sum, for that region, of total agricultural production of each crop, for normal years, taking into account the corresponding average sale price and the potential extra cost associated to livestock feeding), so as to obtain one single value representative of the agricultural drought impacts severity in the area.

For the urban water supply the aggregation of the economic impacts due to drought, defined as correspondent to the additional costs needed to overcome systems' limitations, are compared with the total costs due to urban water supply, in the same area, on a normal year, quantified by multiplying the corresponding total volume of water supplied by the averaged total unit water supply cost, per $\mathrm{m}^{3}$, following INSAAR data (INAG 2009).

Each of these final numbers will express drought impacts' relevance, according to the economic dimension of the agricultural or water supply sectors for that area, and may be used to picture drought severity maps for each sector, for a particular hydrological year.

Nonetheless (case (ii) referred above), a global aggregation for the area in analysis may also be obtained. In order of that, a sum of the economic impacts of the various sectors and subsectors for the spatial scale considered shall be performed, in order to compare with an estimation of the Gross Domestic Product (GDP) of the corresponding area. The ratio of the overall estimated economic impacts by the GDP of the area will be representative of the expected final aggregated results, reflecting the socioeconomic drought impact severity for that region.

Since all of these assessments are based on the relative comparison of the estimated impacts with the economic importance of the subsector, sector or region, it is possible to compare, directly, the relevance of drought impacts in each sector, or also of the overall impacts in different regions, or drought situations.

Moreover, in both cases (analysis of impacts for each sector, or overall impacts for the region), specific socioeconomic drought severity classes can be defined, according to the importance of the impacts, and the objectives of decision making. For the referred case studies, the drought severity classes (and indicative trigger values) considered are presented: in Table 1a, for the assessment of the agricultural sector and subsectors; in Table 1b, for the assessment of the urban water supply sector, and; in Table 2, for the assessment of regional overall impacts.

Based on the classification presented, the assessment of drought situations for each of the two case study regions analysed can be performed. Naturally, the definition of the severity

Table 1 Classification scales of the socioeconomic drought assessments for the (a) agricultural sector and subsectors and (b) urban water supply sector, by reduction of income or increasing of cost, respectively

\begin{tabular}{lc}
\hline \multicolumn{2}{c}{ a) Scale used for agriculture (\% $€$ of Income) } \\
\hline Regular & 0 to $15 \%$ \\
Mild drought & 15 to $30 \%$ \\
Severe drought & 30 to $50 \%$ \\
Extreme drought & 50 a $100 \%$ \\
\hline
\end{tabular}

\begin{tabular}{ll}
\hline b) Scale used for urban water supply (\% $€$ of Costs) \\
\hline Regular & 0 to $5 \%$ \\
Mild drought & 5 to $10 \%$ \\
Severe drought & 10 to $25 \%$ \\
Extreme drought & 25 a $100 \%$ \\
\hline
\end{tabular}


Table 2 Classification scales of the socioeconomic drought assessment of regional overall impacts as a $\%$ of region's GDP

\begin{tabular}{lc}
\hline \multicolumn{2}{l}{ Scale used for regional impacts $(\% €$ of GDP) } \\
\hline Regular & 0 a $1,5 \%$ \\
Mild Drought & 1,5 a $3,0 \%$ \\
Severe Drought & 3,0 a $5,0 \%$ \\
Extreme Drought & $>5,0 \%$ \\
\hline
\end{tabular}

classes shall be defined and validated in accordance with the historical register of drought impacts specific to each study region.

\subsection{Analysis of Results for a Severe Past Drought Situation}

In order to validate the methodology application for the Guadiana and Ribeiras do Algarve case studies', a very significant and recent drought situation in Portugal, was considered: the 2004/05 hydrological year, ranked as the worst drought situation of the last 60 years, in terms of area covered by severe or extreme drought level, based on PDSI classification.

For the quantification of water deficits real, data records of rainfall for the area and of surface water storage volumes and groundwater tables for water sources and of water uses for the region were used (INAG 2011).

Figure 1 depicts an example of the drought severity maps obtained for the Portuguese area of the Guadiana region, for each of the analysed sectors and subsectors. It shall be noticed that a division into six spatial Units of Analysis (UA, numbered 1 to 6) was considered, those defined regarding: (i) the divisions into sub-basins; (ii) the location of the main water uses and of the corresponding water sources, and; (iii) the jurisdictional areas of the water management organizations.

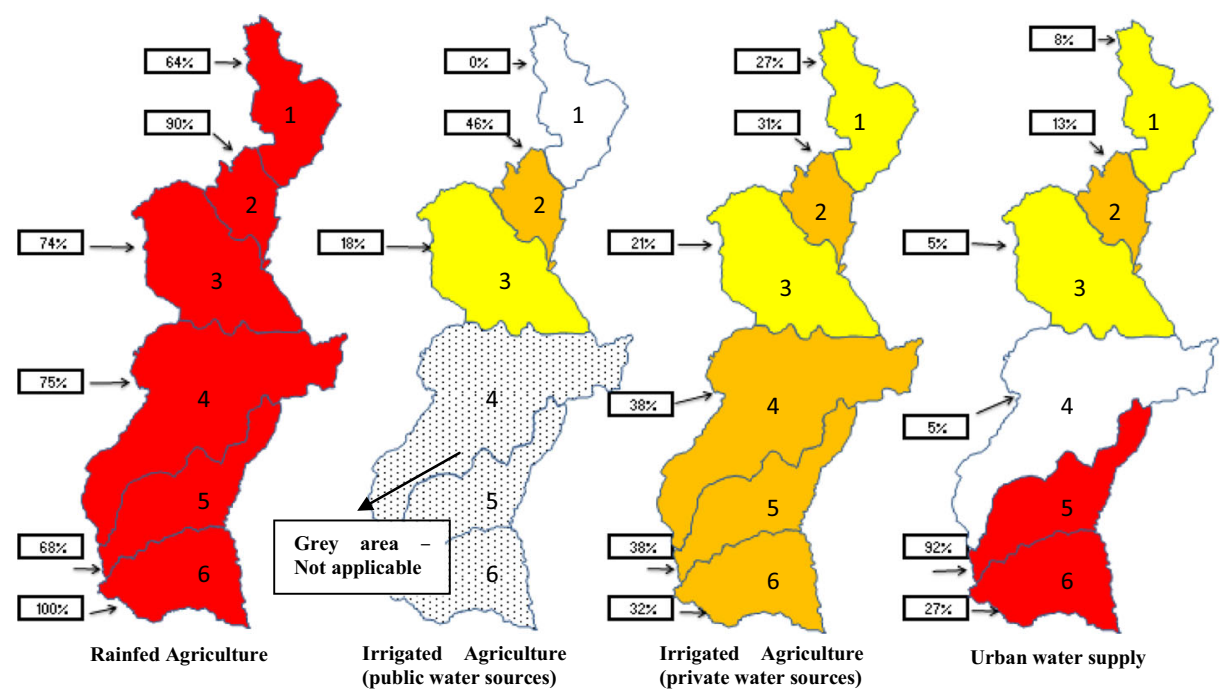

Fig. 1 Results for the different sectors and subsectors of the socioeconomic assessment of drought, for Guadiana, on the 2004/05 hydrological year 
It is possible to verify that for each sector, there are some UAs more affected than others and also that, for this particular drought situation and case study region (Guadiana) the rainfed agricultural subsector suffered the more severe effects.

In Fig. 2, a drought severity map for the overall impacts, for the same region and drought situation, is presented. It shall also be noticed that the water storage of Alqueva reservoir (one of the largest reservoirs in Europe, located in Guadiana river, and the main storage of Spanish inflows), was still, by that time, beginning to be of use, since the infrastructures to link to the main (agricultural) areas of water use were still under construction.

Globally, from Fig. 2, it can be observed that UA 5 was the most affected area of the entire Guadiana basin. Comparing the sector and sub-sector results (Fig. 2) with the existing impact records for that drought situation it is possible to confirm that rainfed agriculture was the main impacted sub-sector, and that the municipalities within UA 5 area were also those with more serious problems in reality (CPS 2005).

Moreover, it should be enhanced that although the present analysis is based on real past data (of precipitation and water volumes in sources), a similar assessment can be applied considering possible future scenarios of rainfall, at annual scale, and the corresponding simulation of water sources availabilities. Those prospective results can, then, be used for identification of the most probable affected areas and where drought preventive and/or mitigating measures need to be adopted, fostering the envisaged support for drought management and application on a drought early warning system for Portugal.

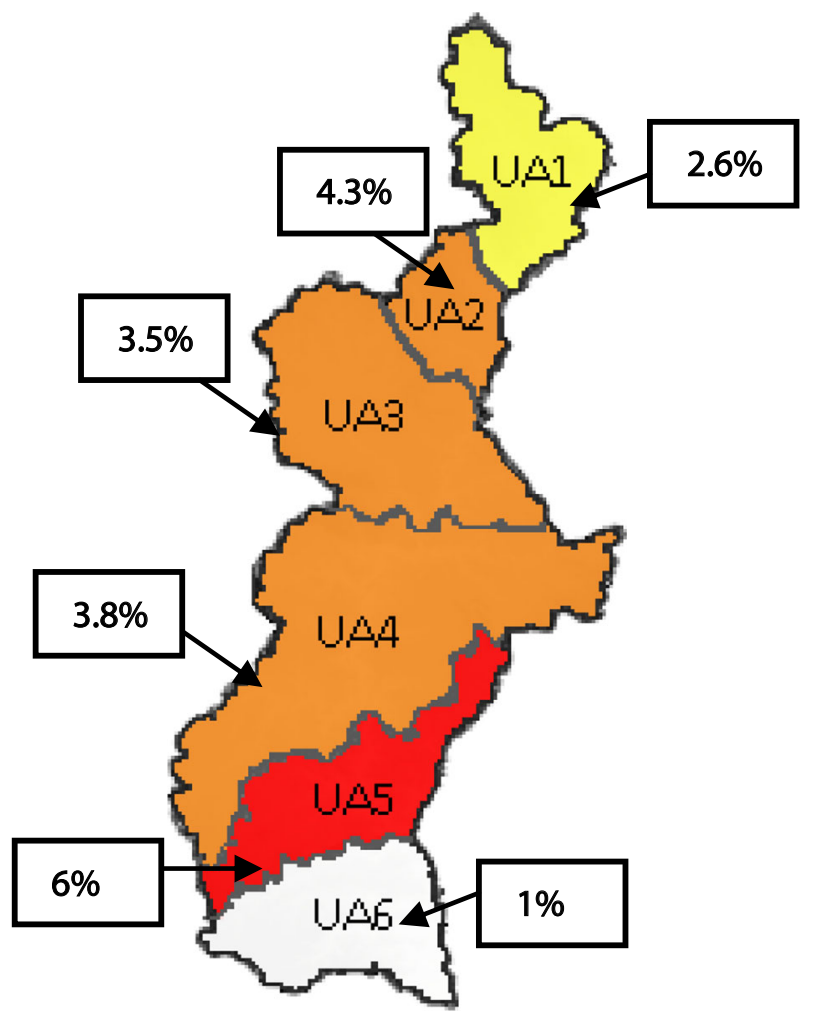

Fig. 2 Results for the socioeconomic assessment of overall drought impacts for each UA, for Guadiana, on the 2004/05 hydrological year 


\section{Conclusions}

As a result of the present work, it is possible to conclude that the socioeconomic evaluation of drought effects can be an important methodology for drought severity assessment. This type of procedure can improve the identification of drought impacts in a certain region, linking the possible reduction of rainfall to effective impacts in different water users and regions. Moreover, it enables the comparison of results for different sectors, distinct regions and drought events, since it relates the importance of drought impacts with the economic relevance and support of the sector and region.

The application herein presented for the Guadiana and Ribeiras do Algarve case studies was based on the assessment of potential impacts on agriculture and urban water supply sectors, since these were considered the more significant water users in both regions. For agriculture, the procedure (distinguishing rainfed and irrigated crops production) is based on assessing the decrease on framers' income compared to a normal year (both by a reduction of crop yields or an increase in the production costs). For urban water supply the evaluation method regards the estimation of additional costs of using alternative water sources to avoid water shortages.

The methodology may be applicable to any region with common hydrological and water use data and may be of support for drought management and for application on a drought early warning system.

\section{References}

Agnew (2000) Using the SPI to identify drought. Drought Network news, Vol. 12, No1, Winter 1999-Spring 2000

Allen R, Pereira LS, Raes D, Smith M (1998) Crop evapotranspiration: guidelines for computing crop water requirements. FAO Irrigation and Drainage, Paper No. 56, Rome, Italy, 300pp

Alley W (1984) The palmer drought severity index: limitations and assumptions. U.S. Geological Survey, Reston

Alston M, Kent J (2004) Social impacts of drought. A report to NSW Agriculture, Centre for Rural Social Research, Charles Stuart University, ISBN 1864671491

ARH-Alentejo (2012) Plano de Gestão de região hidrográfica do Guadiana (Water Resources Management Plan for the Portuguese area of Guadiana's river basin). ARH Alentejo, MAMAOT, 2012

Birol E, Karousakis K, Koundouri P (2006) Using economic valuation techniques to inform water resources management: a survey and critical appraisal of available techniques and an application. Sci Total Environ $365(1-3): 105-122$

Colby B (1989) Estimating the value of water in alternative uses. Nat Res J 29(2):511-527

CPS (2005) Seca em Portugal Continental - Relatório Quinzenal (biweekly 2005's Drought follow up reports in mainland Portugal, published from 1st of March to the 31st of December 2005). Technical secretariat for the 2005's Drought Commission, Instituto da Água, MAOTDR

DG Env EC (2007a) Water Scarcity \& Droughts. In-depth assessment, Second Interim Report, Directorate General Environment, European Commission, Brussels

DG Env EC (2007b) Drought management plan report. Including Agricultural, Drought Indicators and Climate Change Aspects, Water Scarcity and Droughts Experts Network, Directorate General Environment, European Commission, Brussels

Ding Y, Hayes M, Wildham M (2011) Measuring economic impacts of drought: a review and discussion. Disaster Prev Manag 20(4):434-446. doi:10.1108/096535611111161752

Dixon LS, Moore NY, Pint EM (1996) Drought management policies and economic effects in urban areas of California. 1987-1992, California Urban Water Agencies, ISBN 0-8330-5467-1

Doorenbos J, Kassam A (1979) Yield response to water. FAO Irrigation and Drainage Paper 33, Rome

Gibbons DC (1986) The economic value of water. Resources for the Future, Washington, D.C

Green C (2003) Handbook of water economics -principles and practices. ISBN 0-471-98571-6

Iglesias A, Moneo M, Quiroga S (2009) Methods for evaluatng social vulnerability to drought. Book chapter in Iglesias, A., Garrote, L., Cancelliere, A., Cubillo, F., Wilhite, D. (eds), Coping with Drought Risk in Agriculture and Water Supply Systems, Advances in Natural and Technological Hazards Research 26, Springer, ISBN 978-1-4020-9044-8, pp 153-159 
INAG (2009) Inventário nacional de sistemas de abastecimento de água e de águas residuais (numeric and spatial referenced data of the Portuguese national inventory of water supply and wastewater drainage systems, year of 2008). Instituto da Água, I.P

INAG (2011) Sistema Nacional de Informação de Recursos Hídricos (National online information system on water resources), INAG, data collected in 2011, available online in http://snirh.pt/

INE (2011) Recenseamento Agrícola (National Agricultural Inquiry) 2009

Jenkins MW, Lund JR, Howitt RE (2003) Economic losses from urban water scarcity in California. Journal of the American Water Works Association 95 (2), February

Kraemer R (2007) Economic impact of droughts: challenges for water \& environmental policies. water scarcity and drought - a priority of the Portuguese Presidency, Ministério do Ambiente, Ordenamento do Território e Desenvolvimento Regional, ISBN 978-989-8097-08-8, pp 61-88

Markandya A, Mysiak J (2010) The economic costs of drought. Options Méditerranéennes, A no. 95, 2010 Economics of drought and drought preparedness in a climate change context

McKee TB, Doesken NJ, Kleist J (1993) The relationship of drought frequency and duration of time scales. Eight Conference on Apllied Climatology, American Meteorological Society, Jan 17-23, Anaheim CA, pp. 179186

Palmer WC (1965) Meteorologic drought. U.S. Weather Bureau, Research Paper 45, 65pp

Pereira LS (2007) Drought impacts in agriculture: water conservation and water saving practices and management, in Rossi, G., Vega, T., Bonaccorso, B. (eds), Methods and tools for Drought Analysis and Management, Springer, ISBN 978-1-4020-5923-0, pp 349-373

Raucher R, Chapman D, Henderson J, Hagenstad M, Rice J, Goldstein J, Huber-Lee A, Deoreo W, Mayer P, Hurd B, Linksy R, Means E, Renwick M (2005) The value of water: concepts, estimations and applications for water managers. AWWA

Sartore G, Kelly B, Stain H (2007) Drought and its effect on mental health - How GPs can help. Aust Fam Physician 36(12):990-993

Serralheiro R, Carvalho M, Corte-Real J, Toureiro C (2010) Sistema de Previsão e Gestão de Secas (SPGS) Relatórios 1 a 4, 2009 e 2010. ICAAM, Universidade de Évora

Steinmann A, Hayes M, Cavalcanti L (2005) Drought indicators and triggers, in drought and water crises: science, technology and management issues, Wilhite, D. (ed), CRC press - Taylor \&Francis group, ISBN: 0847-2771-1, pp.71-92

Strosser P, Dworak T, Delvaux PAG, Berglund M, Schmidt G, Mysiak J, Kossida M, Iacovides I, Ashton V (2012) Gap analysis of the water scarcity and droughts policy in the EU - final report. Acteon Environment Research and Consultancy, European Commission Temder ENV.D.1/SER/2010/0049, August 2012

Teixeira JL, Pereira LS (1992) ISAREG, an irrigation scheduling model. ICID Bull 41(2):29-48

Valiñas M (2006) Analysing rationing policies: drought and its effects on urban users' welfare (Analysing rationing policies during drought). Appl Econ 38(8):955-965

Vivas E (2011) Avaliação e gestão de situações de seca e escassez. Aplicação ao caso do Guadiana (Assessment and management of droughts and water scarcity situation. Application to the Guadiana case). $\mathrm{PhD}$ thesis in Civil Engineering, Faculdade de Engenharia da Universidade do Porto, Porto

Vivas E, Maia R (2013) Economic valuation of drought impacts on urban water supply systems. Application to a Portuguese drought prone area. Paper for EWRA 8th International Conference "Water Resources Management in an Interdisciplinary and Changing Context", 26th-29th June 2013, Porto, EWRA (submitted)

Ward FA, Young R, Lacewell R, King JP, Frasier M, McGukin JT, Dumars C, Booker J, Ellis J, Srinivasan R (2001) Institutional Adjustements for Coping with Prolonged and Severe Drought in the Rio Grande Basin. Technical Completion Report No. 317, New Mexico WRRI, Texas WRRI, Colorado WRRI

Ward FA, Booker JF, Michelsen A (2006) Integrated economic, hydrologic and institutional analysis of policy responses to mitigate drought impacts in rio grande basin. Journal of Water Resources Planning and Management, ASCE, November-December

Wilhite D (2009) Drought monitoring as a component of drought preparedness planning - chapter 1, in Iglesias, A., Garrote, L., Cancelliere, A., Cubillo, F., Wilhite, D. (eds), Coping with Drought Risk in Agriculture and Water Supply Systems, Advances in Natural and Technological Hazards Research 26, Springer, ISBN 9781-4020-9044-8, pp 3-19

Wilhite D, Buchanan-Smith M (2005) Drought as hazard: understanding the natural and social context, in Wilhite, D. (ed.), Drought and Water Crises - Science, Technology and Management issues, Taylor \& Francis, ISBN 08472771 1, pp 3-29

Wilhite D, Svoboda M, Hayes M (2007) Understanding the complex impacts of drought: a key to enhancing drought mitigation and preparedness. Water Resour Manag 21:763-774 